\title{
DOEJER/6/205-1
}

\section{Ultrafine Aerosol Size Distributions and sulfuric acid vapor pressures: Implications for new particle formation in the atmosphere}

DOE Grant No. DE-FG02-91ER61205

Peter H. McMurry, PI

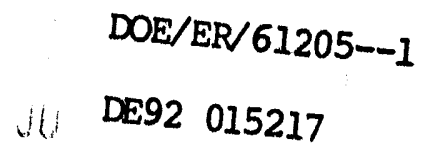

\section{Year 1 Progress Report}

This project has two components with different but related objectives. One component deals with measurement of $\mathrm{H}_{2} \mathrm{SO}_{4}$ vapor pressures in air under temperature and relative humidity conditions similar to those found in the atmosphere. The second deals with measurement of ultrafine aerosol size distributions. Substantial progress has been made on each of these projects.

\section{Sulfuric acid vapor pressures.}

Mr. Chad Richert completed a M.S. Thesis on this topic in October, 1991. The latter stages of this work were supported by this DOE grant. His stipend ciuring early stages was obtained from other funds. Since October, 1991, Ms. Xiaoping Cai, a visitor from China, has been working on this project. Ms. Cai plans to stay with us until October 1992. In the following paragraphs the results of Mr. Richert's thesis research are summarized.

Mr. Richert produced ultrafine aerosols by evaporating a sulfuric acid aerosol in a tube furnace. At the exit from the furnace the sulfuric acid was nucleated to polydisperse ultrafine particles by quenching with cool air. Monodisperse particles $(0.05$ to $0.15 \mu \mathrm{m})$ were selected from this polydisperse aerosol with a differential mobility analyzer. These monodisperse aerosols were blended with dry air at a known temperature. The diluter aerosol flowed into i temperature controlled, laminar flow evaporator tube where evaporation rates were measured by using a second differential mobility analyzer to measure the initial and final particle size. The temperature and relative humidity in the evaporator tube were $34.6 \pm 0.1 \mathrm{C}$ and $7-8 \%$, respectively, and typical evaporation times were 160 seconds.

Selected results from Mr. Richert's work are shown in Figure 1. The ordinate shows the ratio of the final (after evaporation) to initial (at the start of the evaporation period) particle diameters, while the abscissa shows the initial diameter. In addition to the data two sets of lines are shown. The three lines to the left show the range of expected results assuming that the vapor pressure is one tenth of that predicted by Gmitro and Vermeulen (1964), while the three lines to the right show the range of expected results assuming that the results of Gmitro and Vermeulen are correct. The ranges take account of uncertainties in experimental temperature and relative humidity. As discussed in the original proposal, several previous researchers (e.g., Rocdel, 1979; Ayers et al., 1980; Richardson et al., 1986) concluded that the correct value should be about one tenth the value predicted by Gmitro and Vermeulen. At first glance one r.aight conclude that our work is consistent with the results of the se other researchers.

The evaporator tube has eight ports which permit measuring particle size as a function of time. The initial and final measurements in Figure 1 were made at ports 1

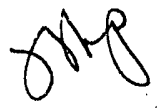


and 6. Richert (1991) conducted other experiments in which particle sizes at intermediate ports were measured. Typical results of these measurements are shown in Figure 2. Note that early in the evaporation process the particles evaporated relatively quickly, at a rate consistent with the vapor pressures predicted by Gmitro and Vermeulen (1963). As time progressed, however, evaporation rates decreased to values more consistent with values equal to one tenth those predicted by $\mathrm{Gmitro}$ and Vermeulen. Because evaporation rates varied with time, we cannot conclude that the results shown in Figure 1 are valid.

We have been exploring several hypotheses to understand the reas 7 for the decrease in evaporation rates shown in Figure 2. One possibility is that the aerosol particles contain nonvolatile impurities that become increasingly concentrated as evaporation progresses. If this were the case then the higher vapor pressures measured early in the droplet evaporation process would be more nearly correct than the later values. Another possibility is that the droplets are reacting with a gas-phase contaminant (e.g., $\mathrm{NH}_{3}$ ) which is leading to a change in composition and a subsequent decrease in volatility. Again, if this were occurring then the initial evaporation rates would be more nearly correct. Alternatively, the high initial rates could be associated with the presence of a volatile contaminant in the droplets that evaporates quickly during the early stages of evaporation. In this case the lower, as' . rotic, values for vapor pressure would be more nearly correct.

Future work will be directed towards determining whether the fast or slow evaporation rates are more nearly correct. The approach that is being taken is summarized in the section on proposed Year 2 research.

\section{Ultrafine Aerosol Measurement}

We were fortunate to have Mr. Pasi Aalto, Department of Physics, University oi Helsinki, visit our laboratory with support from the Nessling Foundation from January 1991 through December 1991. Mr. Aalto was assigned the task of modifying our laboratory prototype ultrafine aerosol condeilsation nucleus counter to measure sub $10 \mathrm{~nm}$ size distributions. Both the pulse height analysis and the variable temperature condenser modes were implemented (see original proposal). The instrument was interfaced to a microcomputer for routine data recording. This work was completed by June, 1991. Mr. Aalto then took the instrument to the Arctic Ocean to measure size distributions of ultrafine particles in the marine boundary layer. Participation in the International Arctic Ocean Expedition 1991 was in response to an invitation from Dr. Jost Heintzenberg, University of Stockholm. The Swedish icebreaker Oden was the platform for these measurements. The measurement period was approximately 1 August, 1991 through 10 October, 1991, and traversed a route through the North Pole. Mr. Rodney Weber, a $3^{\text {rd }}$ year graduate student, plans to complete his Ph.D. research working on ultrafine aerosol measurements with support from this grant.

The response of the instrument to monodisperse ultrafine particles is shown in Figure 3. Similar calibration results are obtained for both sulfuric acid and sodium chloride particles, indicating that for these species particle chemical composition does not play a major role in the condensation process. These data were obtain $\bullet d$ by feeding monodisperse ultrafine particles into the ultrafine aerosol condensation nucleus counter. The particles grew from their initial size (shown in the figure title) to a final size that was typically two to three orders of magnitude larger than the initial size. These large druplets were detected optically. Pulse heights from the optical detector were measured and classified with a multi channel analyzer (MCA). The ordinate on the plot shows the number of counts in a given MCA channel; the abscissa identifies the channel number. 
Figure 1: Theoretical vs. Experimental Shrinkage

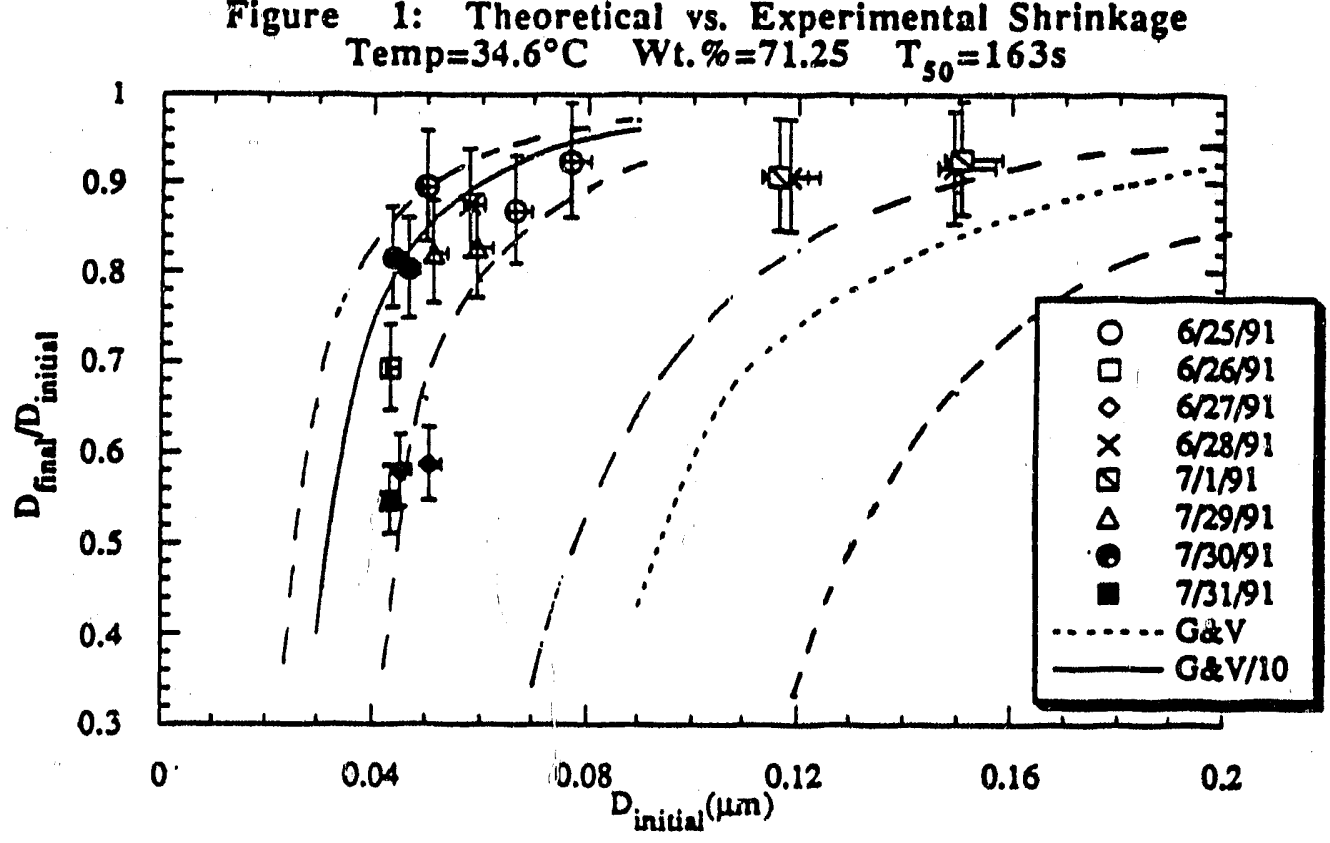

Fygure 2 : Vapor Pressures of $\mathrm{H}_{2} \mathrm{SO}_{4}$ at $34.6^{\circ} \mathrm{C}$ and $\mathrm{Rh}=7.15 \%$ Taken on $8 / 20 / 91 \quad D_{\text {loftlal }}=0.0700 \mu m$

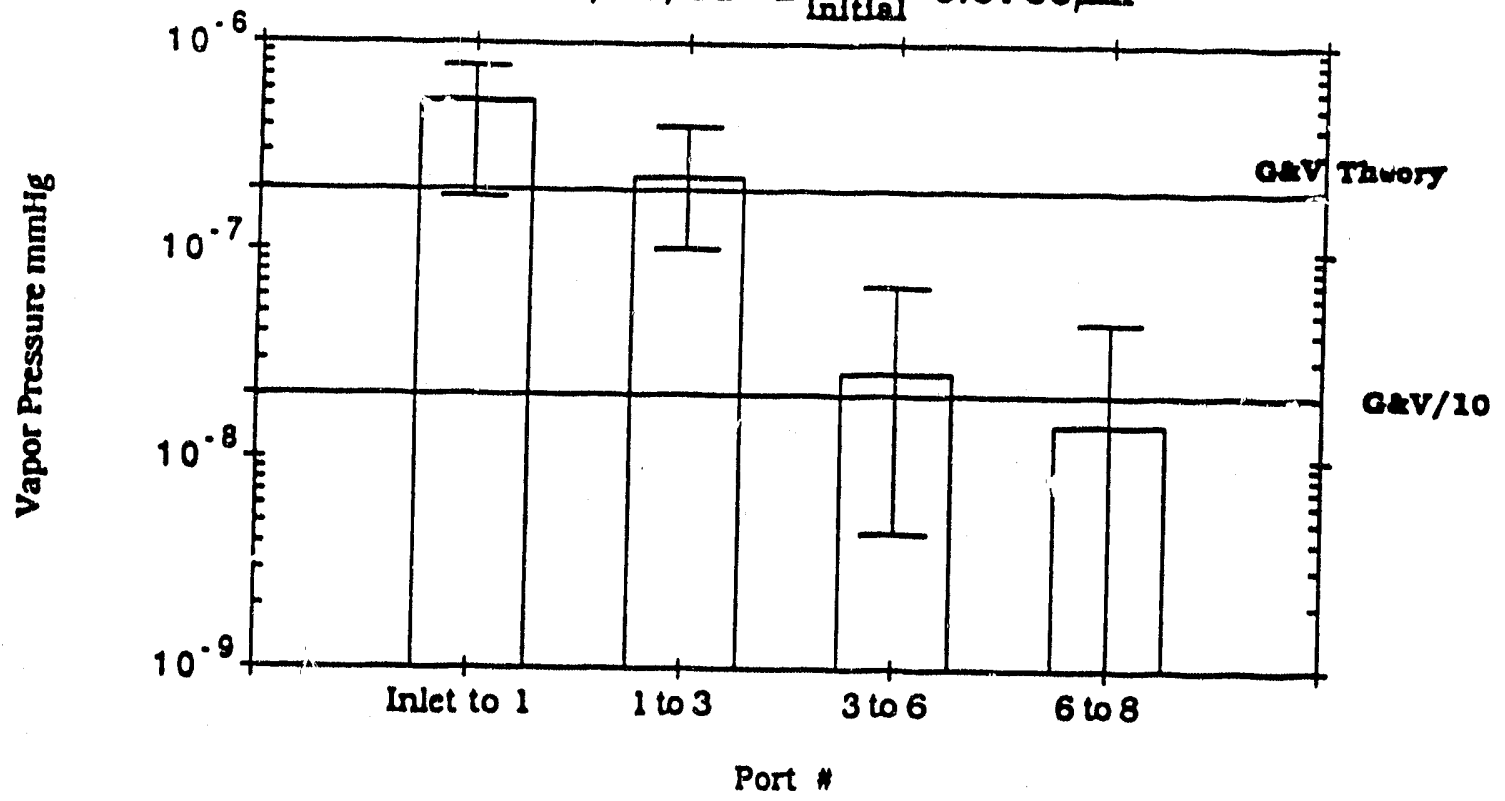


Figure 3

Calibration for UFCNC pulse height counting mode.

Particle diameters are:

$3.0,3.5,4.0,4.5,5.0,6.0,8.0,10.0$ and $13.0 \mathrm{~nm}$.

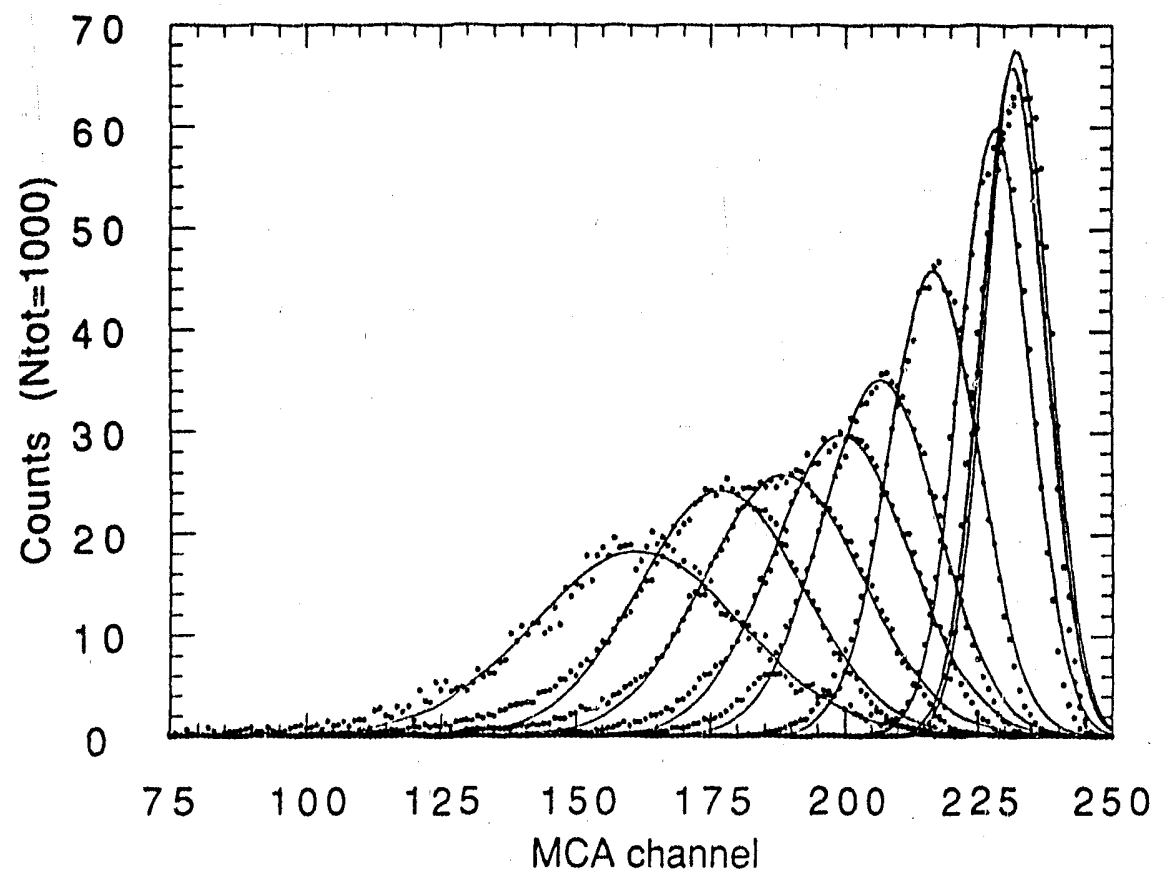

Figure 4

Calibration for UFCNC variable temperature mode.

Particle diameters are: $3.0,3.5,4.0,4.5,5.0$,

$6.0,7.0,8.0,9.0,10.0,11.0,12.0$ and $13.0 \mathrm{~nm}$.

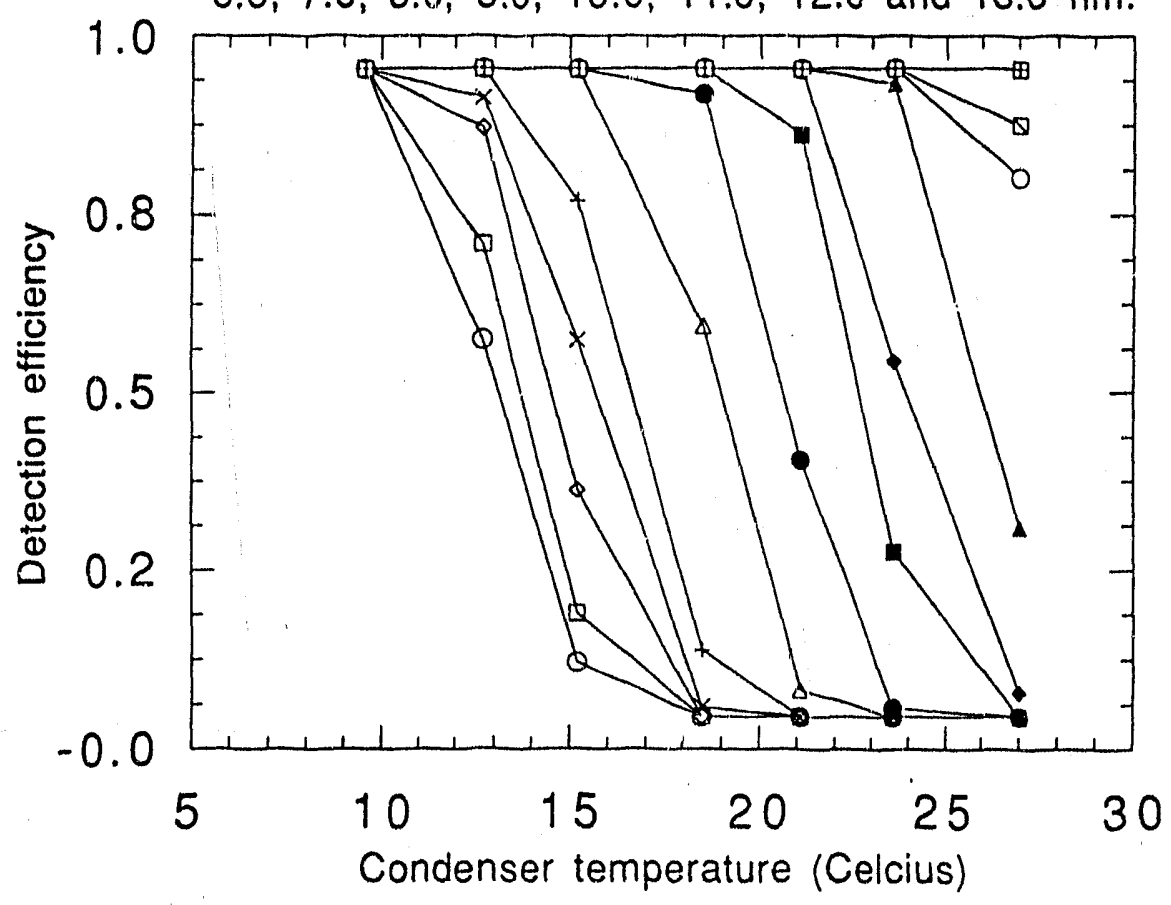


Higher channel numbers correspond to more scattered light (i.e., to larger droplet sizes). Note that for particle sizes smaller than about $8 \mathrm{~nm}$ there is a well defined relationship between pulse height and initial particle size. This occurs because the small particles require a relatively high supersaturation to initiate growth. The saturation ratio to which the particles are exposed increases with axial distance in the condenser. Thus the small particles need to travel further into the condenser before they start to grow, and they therefore have less time to grow before entering the optical detector. Particles larger than about $10 \mathrm{~nm}$ all begin to grow near the inlet to the condenser, and therefore all grow to about the same final size. Therefore, no useful information on particle size distributions can be obtained for particles larger than $10 \mathrm{~nm}$ using this approach.

The response of the instrument to monodisperse particles in the variable condenser temperature mode is shown in Figure 4. Again, calibrations are shown for monodisperse aerosols of various sizes (see Figure title). Note that the counting efficiency shows a clear dependence on the condenser temperature: as the temperature increases, the minimum detectable particle size also increases. We developed a computer-controlled interface that permitted automatically setting the condenser temperature.

During the Arctic expedition, both the pulse height analysis and the variable condenser temperature modes were used. We found that for ambient measurements in the marine boundary the pulse height analysis mode is preferable. In the variable temperature mode, size distributions are determined by measuring the change in measured concentration that is observed when the condenser temperature changes. Because changes can occur as a result in the natural variability in aerosol concentrations as well as because of changes in the condenser temperature, we found that the variable temperature mode data was noisy. On the other hand, the pulse height analysis mode is unaffected by changes in concentration: every particle produces a useable signal.

The data from the summer Arctic Ocean measurements show clearly that sub $6.5 \mathrm{~nm}$ particles were frequently present. We believe that these particles were produced by homogeneous nucleation as a result of atmospheric photochemical transformations. We are currently working in collaboration with other expedition researchers in order to infer possible chemical sources for these particles.

\section{DISCLAIMER}

\footnotetext{
This report was prepared as an account of work sponsored by an agency of the United States Government. Neither the United States Government nor any agency thereof, nor any of their employees, makes any warranty, express or implied, or assumes any legal liability or responsibility for the accuracy, completeness, or usefulness of any information, apparatus, product, or process disclosed, or represents that its use would not infringe privately owned rights. Reference herein to any specific commercial product, process, or service by trade name, trademark, manufacturer, or otherwise does not necessarily constitute or imply its endorsement, recommendation, or favoring by the United States Government or any agency thereof. The views and opinions of authors expressed herein do not necessarily state or reflect those of the United States Government or any agency thereof.
} 
s.
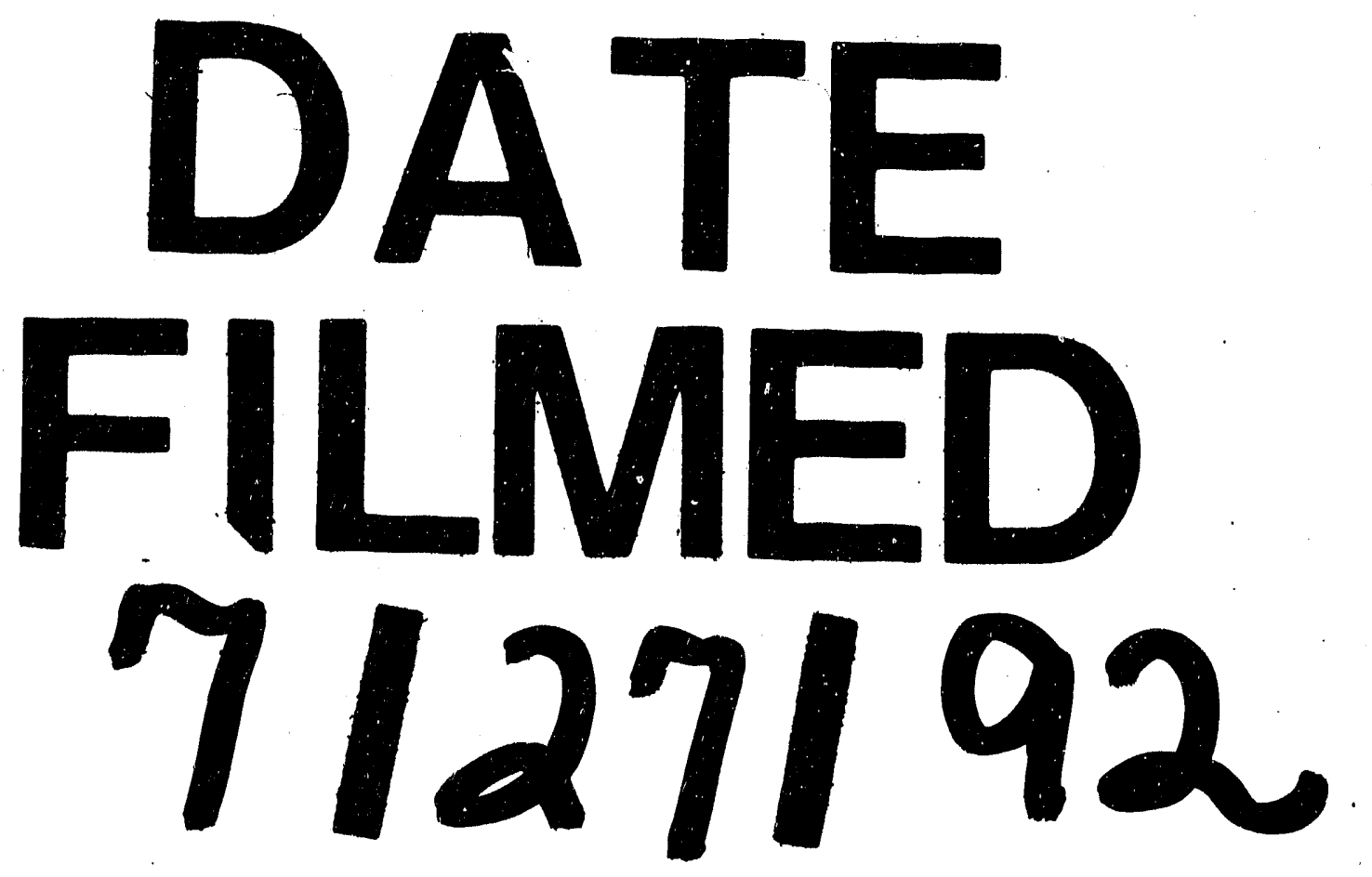
